\title{
Fertilização fosfatada na implantação de Khaya senegalensis A. Juss.
}

\author{
Phosphurus fertilization in Khaya senegalensis A. Juss. implantation
}

\author{
Rodrigo Tenório de Vasconcelos ${ }^{1}$, Sérgio Valiengo Valeri² ${ }^{2}$ Mara Cristina Pessôa da Cruz ${ }^{3}$, \\ José Carlos Barbosa ${ }^{4}$ e Vitor Corrêa de Mattos Barretto ${ }^{5}$
}

\begin{abstract}
Resumo
A fertilização na implantação de florestas comerciais de mogno-africano pode promover maior crescimento inicial das plantas e garantir o estabelecimento rápido do povoamento. No entanto, os plantios comerciais com Khaya senegalensis são recentes e poucas pesquisas sobre fertilização em condições de campo foram realizadas no Brasil. Com o presente trabalho objetivou-se verificar os efeitos da aplicação de doses de fósforo no crescimento, na concentração de macronutrientes nas folhas, na condutância estomática, na transpiração, na fotossíntese e na eficiência do uso da água em plantas de Khaya senegalensis na fase de implantação. No plantio, foram aplicados 0, 30, 60, 90 e $120 \mathrm{~kg} \mathrm{ha}^{-1}$ de $\mathrm{P}_{2} \mathrm{O}_{5}$ em Argissolo Vermelho-Amarelo e as mudas foram plantadas no espaçamento de $3 \times 2 \mathrm{~m}$, em janeiro de 2014. O delineamento experimental foi o de blocos ao acaso com cinco repetições. Foram feitas avaliações de altura e diâmetro do caule aos 6,12 , 18 e 24 meses após plantio. Aos 12 meses foi determinada a concentração de macronutrientes nas folhas, a condutância estomática, a transpiração, a fotossíntese e a eficiência do uso da água. A fertilização fosfatada promoveu maior crescimento das plantas no período de um a dois anos de idade, promovendo aumento linear de altura e diâmetro à altura do peito com o aumento das doses de fósforo até a dose máxima de $120 \mathrm{~kg} \mathrm{ha}^{-1}$ de $\mathrm{P}_{2} \mathrm{O}_{5}$.
\end{abstract}

Palavras-chave: argissolo; fertilização florestal; mogno-africano; nutrição.

\begin{abstract}
Fertilization in the implantation of African mahogany commercial forests can promote greater initial plant growth and ensure rapid establishment of the stand. However, the commercial plantations with the species are recent and little research on fertilization under field conditions were carried out in Brazil. The objective of this work was to verify the effects of the application of phosphorus doses on growth, macronutrient concentration in leaves, stomatal conductance, transpiration, and photosynthesis and water use efficiency in plants of Khaya senegalensis in the implantation. At the planting, 0,30,60, 90 and $120 \mathrm{~kg} \mathrm{ha}^{-1}$ of $\mathrm{P}_{2} \mathrm{O}_{5}$ were applied in red yellow ultisol and the seedlings were planted at $3 \times 2 \mathrm{~m}$ spacing in January 2014 . The experimental design was randomized blocks with five replications. Height and stem diameter were evaluated at $6,12,18$ and 24 months after planting. At 12 months the concentration of macronutrients in leaves, stomatal conductance, transpiration, photosynthesis and water use efficiency were determined. Phosphate fertilization promoted greater growth of the plants in the period of one to two years of age, promoting a linear increase in height and diameter at breast height with the increase of phosphorus doses to the maximum dose of $120 \mathrm{~kg} \mathrm{ha}^{-1} \mathrm{P}_{2} \mathrm{O}_{5}$.
\end{abstract}

Keywords: Ultisol, forest fertilization, african mahogany, nutrition.

"Doutor em Agronomia - Produção Vegetal. Unesp - Universidade Estadual Paulista "Júlio de Mesquita Filho" / Faculdade de Ciências Agrárias e Veterinárias. Via de Acesso Prof. Paulo D. Castellane - km 05 - 14884-900 - Jaboticabal, SP, Brasil. E-mail: rodrigotvasconcelos@hotmail.com.

2Professor Titular no Departamento de Produção Vegetal. Unesp - Universidade Estadual Paulista "Júlio de Mesquita Filho" / Faculdade de Ciências Agrárias e Veterinárias. Via de Acesso Prof. Paulo D. Castellane - km 05 - 14884-900 - Jaboticabal, SP, Brasil. E-mail: sergio.valeri1@gmail.com.

3Professor Titular no Departamento de Ciência do Solo. Unesp - Universidade Estadual Paulista "Júlio de Mesquita Filho" / Faculdade de Ciências Agrárias e Veterinárias. Via de Acesso Prof. Paulo D. Castellane - km 05 - 14884-900 - Jaboticabal, SP, Brasil.

${ }^{4}$ Professor Titular no Departamento de Ciências Exatas. Unesp - Universidade Estadual Paulista “Júlio de Mesquita Filho" / Faculdade de Ciências Agrárias e Veterinárias. Via de Acesso Prof. Paulo D. Castellane - km 05 - 14884-900 - Jaboticabal, SP, Brasil.

${ }^{5}$ Professor Doutor no Departamento de Silvicultura e Conservação do Solo. Unesp - Universidade Estadual Paulista / Faculdade de Ciências Agrárias e Tecnológicas. Rodovia Comandante João Ribeiro de Barros - Km 651 - Dracena, SP, Brasil. E-mail: barretto@dracena.unesp.br. 


\section{INTRODUÇÃO}

O gênero Khaya pertence à família Meliaceae e compreende quatro importantes espécies madeireiras comerciais, Khaya ivorensis, Khaya grandifolia, Khaya anthotheca e Khaya senegalensis. Nenhuma delas se distingue substancialmente do mogno-brasileiro (Swietenia macrophylla), nem sob o aspecto fisionômico, nem quanto à qualidade da madeira (LAMPRECHT, 1990).

$\mathrm{Na}$ África, K. senegalensis é encontrada naturalmente desde solos de galeria até solos de savana lateríticos e pedregosos, em altitudes que variam de 0 a $1.800 \mathrm{~m}$ e em precipitações de 700 e 1.750 mm por ano (JOKER; GAMÉNÉ, 2012). Essas variações edafoclimáticas que ocorrem na procedência têm despertado grande interesse por plantios comerciais da espécie, pois conferem a ela ampla adaptação fisiológica e genética, que está sendo domesticada em vários países (ORWA et al., 2009).

No Brasil, K. senegalensis é conhecida como mogno-africano, e a comercialização de sua madeira atinge preço bastante elevado no mercado, tornando-se um excelente investimento a médio prazo (PINHEIRO et al., 2011). O preço FOB da sua madeira para exportação no Oeste da África, segundo a Internacional Tropical Timber Organization, é de 450 a 460 por $\mathrm{m}^{3}$ (ITTO, 2016) e os custos de implantação e manutenção da florestas são compensados já com as receitas do $6^{\circ}$ e $12^{\circ}$ ano, produzindo do $17^{\circ}$ ao $25^{\circ}$ ano uma receita líquida de 140 mil dólares por hectare, sem contar o aproveitamento das sementes, que podem ser comercializadas a partir do $20^{\circ}$ ano para formação de mudas (LIMA, 2002).

Os plantios no Brasil e no mundo são recentes e estão em expansão. Na Austrália, um dos primeiros países a ser introduzida, os plantios comerciais somavam, em 2007, 1.500 hectares (NIKLES et al., 2008). No Brasil, segundo informação da Associação Brasileira de Plantadores de Mogno Africano, existem hoje mais de 10.000 hectares plantados com idades de 1 a 7 anos (ABPMA, 2016).

Como os plantios são recentes, há necessidade de pesquisas sobre a nutrição do mogno-africano (PINHEIRO et al., 2011) e, em avaliações preliminares, por meio de levantamentos de plantios comerciais jovens de K. senegalensis na Austrália, foram observados sintomas de deficiências de fósforo e respostas positivas à fertilização fosfatada no crescimento de K. senegalensis (BEVEGE et al., 2006). Esses resultados necessitam ser detalhados por pesquisas locais que determinem os níveis críticos do nutriente no solo e as doses adequadas de fertilizantes para garantir a produtividade dos plantios comerciais de K. senegalensis (NIKLES et al., 2008).

Diante do exposto, o objetivo do presente trabalho foi verificar os efeitos da aplicação de doses de fósforo no crescimento, concentração de macronutrientes nas folhas e nas trocas gasosas de $K$. senegalensis na fase de implantação.

\section{MATERIAL E MÉTODOS}

\section{Área de estudo}

O experimento foi implantado em janeiro de 2014 e foi conduzido até janeiro de 2016, na Fazenda São Gabriel, município de Monte Alto - SP. O clima da região é classificado como Cwa - mesotérmico de inverno seco, pelo sistema internacional de Köeppen (1948), apresentando temperatura média anual máxima de $28{ }^{\circ} \mathrm{C}$ e mínima de $15^{\circ} \mathrm{C}$. A precipitação média anual é de aproximadamente $1.440 \mathrm{~mm}$, com $85 \%$ do total de chuvas concentradas nos meses de outubro a março. A umidade relativa média do ar é de 75\% (CEPAGRI, 2015). O solo da região é classificado como Argissolo Vermelho-Amarelo e relevo suave ondulado (PVA) (OLIVEIRA,1999). Na Figura 1 estão as médias mensais de temperatura e precipitação medidas de janeiro de 2014 a janeiro de 2016, na estação climatológica da Faculdade de Ciências Agrárias e Veterinárias da Universidade Estadual Paulista - FCAV/UNESP, câmpus de Jaboticabal (SP), que dista $20 \mathrm{~km}$ do local do experimento.

\section{Histórico e preparo da área}

A área do experimento permaneceu sem cultivo e adubação por mais de 10 anos. Em dezembro de 2013, foi feita dessecação de gramíneas na área através da aplicação de glifosato e gradagem pesada para incorporação do material vegetal.

A área do experimento permaneceu sem uso ou cultivo agrícola por mais de 10 anos. O solo foi classificado como Argissolo Vermelho-Amarelo distrófico petroplíntico, com horizonte A mo- 
derado, textura arenosa/média (EMBRAPA, 2006). Na área experimental de $5.400 \mathrm{~m}^{2}$ foi coletada uma amostra de solo composta, obtida através de 21 amostras simples, coletadas na camada de $0-20 \mathrm{~cm}$. O resultado da análise granulométrica segundo metodologias de Camargo et al. (2009) evidenciaram 150, 70 e $780 \mathrm{~g} \mathrm{~kg}^{-1}$ de argila, silte e areia respectivamente. O resultado da análise de fertilidade segundo método descrito por Raij et al. (2001) foram: P resina, $3 \mathrm{mg} \mathrm{dm}^{-3} ; \mathrm{MO}^{-2} 2 \mathrm{~g} \mathrm{dm}^{-}$ 3; $\mathrm{pH} \mathrm{CaCl}_{2}, 4,6 ; \mathrm{K}^{+}, 1,6 \mathrm{mmol}_{\mathrm{c}} \mathrm{dm}^{-3} ; \mathrm{Ca}^{2+}, 8 \mathrm{mmol}_{\mathrm{c}} \mathrm{dm}^{-3} ; \mathrm{Mg}^{2+}, 4 \mathrm{mmol}_{\mathrm{c}} \mathrm{dm}^{-3} ; \mathrm{S}, 7 \mathrm{mg} \mathrm{dm}^{-3} ; \mathrm{B}, 0,22$ $\mathrm{mg} \mathrm{dm}^{-3} ; \mathrm{Cu}, 0,6 \mathrm{mg} \mathrm{dm}^{-3} ; \mathrm{Fe}, 60 \mathrm{mg} \mathrm{dm}^{-3} ; \mathrm{Mn}, 7,5 \mathrm{mg} \mathrm{dm}^{-3} ; \mathrm{Zn}, 0,3 \mathrm{mg} \mathrm{dm}^{-3} ; \mathrm{H}+\mathrm{Al}, 34 \mathrm{mmol}_{\mathrm{c}} \mathrm{dm}^{-3}$; CTC a pH 7, $48 \mathrm{mmol}_{\mathrm{c}} \mathrm{dm}^{-3}$; e saturação por bases (V), $29 \%$.
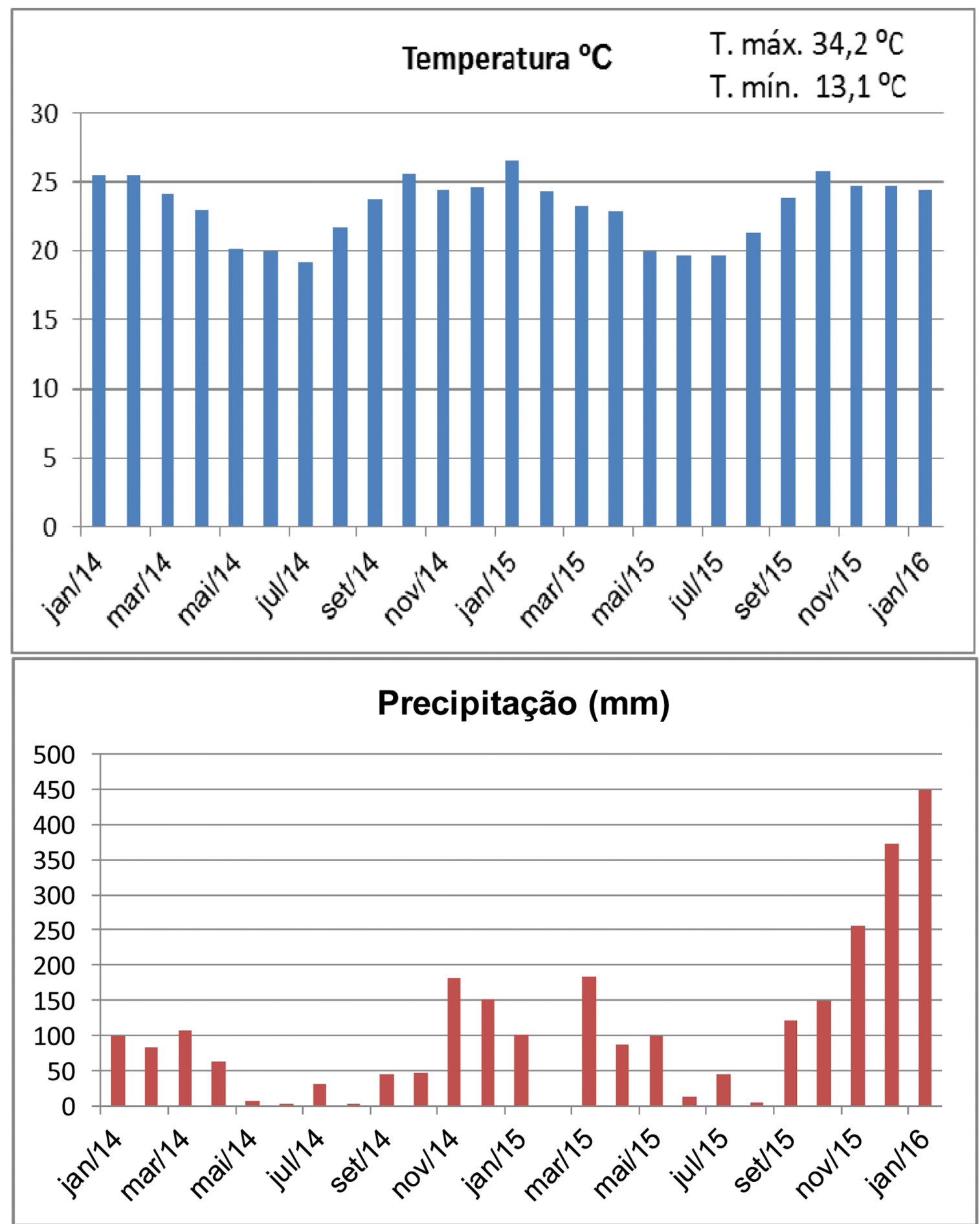

Figura 1. Médias mensais de temperatura, temperatura máxima, temperatura mínima e precipitação registradas na estação climatológica da Faculdade de Ciências Agrárias e Veterinárias da Universidade Estadual Paulista - FCAV/UNESP, câmpus de Jaboticabal (SP), que dista $20 \mathrm{~km}$ do local do experimento, durante o período de jan/2014 a jan/2016.

Figure 1. Monthly mean of temperature, maximum temperature, minimum temperature and precipitation recorded in the climatologic station of the São Paulo State University, Jaboticabal (SP), Brasil, $20 \mathrm{~km}$ from the experiment during Jan/2014 to Jan/2016. 
O calcário, com PNRT 86\% foi aplicado em janeiro de 2014, a lanço em área total e incorporado ao solo com grade pesada para elevar o índice de saturação por bases a $60 \%$. Após sete dias, foi aberto um sulco contínuo de $30 \mathrm{~cm}$ de profundidade determinando as linhas de plantio, no espaçamento de $3 \mathrm{~m}$ entre linhas, com o uso de sulcador tracionado por trator.

\section{Tratamentos e delineamento experimental}

Os tratamentos foram constituídos de cinco doses de fósforo na forma de superfosfato triplo ( 0 , 30, 60, 90 e $120 \mathrm{~kg} \mathrm{ha}^{-1}$ de $\mathrm{P}_{2} \mathrm{O}_{5}$ ) aplicados nas laterais do sulco, linearmente, $50 \mathrm{~cm}$ de cada lado do ponto de colocação da muda. O delineamento experimental foi em blocos casualizados, com cinco repetições.

\section{Produção de mudas, plantio e condução do experimento}

As sementes que deram origem às mudas foram importadas de Honduras, cidade de Siguatepe, cuja procedência é a Aldeia de Tiakane, Burkina Faso (África), situada a $11^{\circ} 11^{\prime} 10^{\prime \prime}$ de latitude norte e $1^{\circ} 12^{\prime} 14^{\prime \prime}$ de longitude oeste. O clima de Burkina Faso é tropical semi-árido, com altas temperaturas, apresentando valor médio anual de $30^{\circ} \mathrm{C}$, e evapotranspiração potencial anual de aproximadamente $2.000 \mathrm{~mm}$. Apresenta estação seca longa, de outubro a maio, e período chuvoso curtocompreendido entre os meses de julho e setembro (COUTERON; KOKOU, 1997). Na Aldeia de Tiakane, a quantidade anual de chuvas não passa de $914 \mathrm{~mm}$ anuais (CLIMATE-DATA, 2016). Os recipientes usados na formação das mudas foram tubetes de plástico, com volume de $120 \mathrm{~cm}^{3}$, contendo substrato Plantmax Florestal ${ }^{\circledR}$, sendo incorporado ao substrato de cada tubete, 1,2 g de Osmocote Plus ${ }^{\circledR}$. Aos 40 dias da semeadura, as mudas foram transferidas para área a pleno sol, aumentou-se o espaçamento entre elas e mantendo a irrigação por 10 minutos a cada hora foi. A partir de 62 dias da semeadura, iniciou-se a rustificação, diminuindo o tempo de cada irrigação para 7 minutos a cada hora.

As mudas com $30 \mathrm{~cm}$ de altura média e $5 \mathrm{~mm}$ de diâmetro médio do coleto foram plantadas no espaçamento $3 \mathrm{~m} \times 2 \mathrm{~m}$, no dia 25 de janeiro de 2014. Cada parcela, com $216 \mathrm{~m}^{2}$, foi formada por seis plantas em seis linhas de plantio, totalizando 36 plantas. As avaliações foram feitas nas 16 plantas centrais, descontando-se a bordadura simples, o que resultou em área útil de $96 \mathrm{~m}^{2}$ por parcela. Após o plantio, foi adicionada cobertura morta com grama seca na coroa das mudas para manutenção da umidade do solo e, na ausência de chuvas, foram realizadas irrigações com tanque pipa e trator, adicionando-se cerca de $5 \mathrm{~L}$ de água por planta até o completo pegamento das mudas.

Todos os tratamentos receberam adubação básica de $60 \mathrm{~kg} \mathrm{ha}^{-1}$ de $\mathrm{K}_{2} \mathrm{O}$, com o uso de cloreto de potássio, e $60 \mathrm{~kg} \mathrm{ha}^{-1}$ de $\mathrm{N}$, com uso de sulfato de amônio, ambos de forma parcelada (1/3 no sulco de plantio, $50 \mathrm{~cm}$ de cada lado do ponto de colocação da muda e os outros $2 / 3$ divididos aos 3 meses e 6 meses do plantio, num raio de $50 \mathrm{~cm}$ da planta).

Durante a condução do experimento de campo, nos primeiros 15 dias foi realizado o replantio das mudas mortas, e durante todo o período do experimento foi realizado o combate a formigas cortadeiras, capinas manuais nas linhas de plantio e mecânicas nas entrelinhas, podas de condução, e manutenção de aceiros para prevenção a incêndios.

\section{Avaliações e análises estatísticas}

Foram feitas avaliações de altura e diâmetro do caule das plantas aos 6, 12, 18 e 24 meses de idade, sendo que, na primeira avaliação o diâmetro do caule foi medido a $20 \mathrm{~cm}$ de altura do solo e, nas demais avaliações, a 1,3 m de altura do solo, referente ao diâmetro à altura do peito (DAP). Para determinar as concentrações de macronutrientes nas folhas, aos 12 meses foi obtida amostra composta de aproximadamente $200 \mathrm{~g}$ de folhas por parcela, coletadas do terço superior e dos quatro pontos cardeais das copas de quatro árvores médias dentro da área útil da parcela. As amostras compostas foram lavadas com água de torneira e com água deionizada. Em seguida, as folhas foram acondicionadas em sacos de papel e colocadas em estufa com circulação forçada de ar a $70^{\circ} \mathrm{C}$ até atingir massa constante. Depois foram processadas em moinho de aço inoxidável do tipo Willey, com peneira de 20 mesh, de acordo com as instruções de Bataglia et al. (1983). Posteriormente, uma porção dessas amostras foram submetidas à digestão nítrico-perclórica para determinação dos teores de $\mathrm{P}, \mathrm{K}, \mathrm{Ca}, \mathrm{Mg}$, S, enquanto outra foi submetida a digestão sulfúrica visando à determinação 
do teor de N. O P foi determinado pelo método da redução do fosfomolibdato pela vitamina C, modificado por Braga e Defelipo (1974); o K, por fotometria de chama; o Ca e Mg, por espectrofotometria de absorção atômica; o S, por turbidimetria do sulfato (BLANCHAR et al., 1963) e o N foi quantificado pelo método colorimétrico de Nessler.

Foram feitas avaliações de condutância estomática, transpiração e fotossíntese aos 12 meses. As avaliações foram realizadas entre $8 \mathrm{~h}$ e $11 \mathrm{~h}$ da manhã, analisando três folhas do terço superior da copa e do ramo de três plantas centrais da parcela, com o uso do IRGA (Infra-Red Gas Analyser modelo LCpro-SD da ADC BioScientific), usando temperatura e umidade ambiente, concentração de $\mathrm{CO}_{2}$ fixada em $380 \pm 10 \mu \mathrm{mol} \mathrm{m}^{-2} \mathrm{~s}^{-1}$ ), fluxo de fótons fotossinteticamente ativo (FFFA) de 1.000 $\mu \mathrm{mol} \mathrm{m} \mathrm{m}^{-2} \mathrm{~s}^{-1}$ correspondente a $80 \%$ do valor máximo de fotossíntese obtido em teste preliminar. A partir dos resultados médios de fotossíntese e condutância estomática, foi estimada a eficiência do uso da água (EUA), com o uso da equação: EUA = fotossíntese/condutância estomática.

Os dados das características avaliadas em função das doses de fósforo foram submetidos à análise de variância pelo teste $\mathrm{F}$. Os efeitos das doses de P nas características da planta foram estudados por equações de regressão polinomial.

\section{RESULTADOS E DISCUSSÃO}

Os efeitos dos tratamentos no crescimento das plantas de K. senegalensis só foram observados a partir de 12 meses de idade, sendo que o aumento das doses de fósforo promoveu um aumento linear de altura e DAP até a dose máxima de $120 \mathrm{~kg} \mathrm{ha}^{-1}$ de $\mathrm{P}_{2} \mathrm{O}_{5}$ (Figuras 2 e 3).
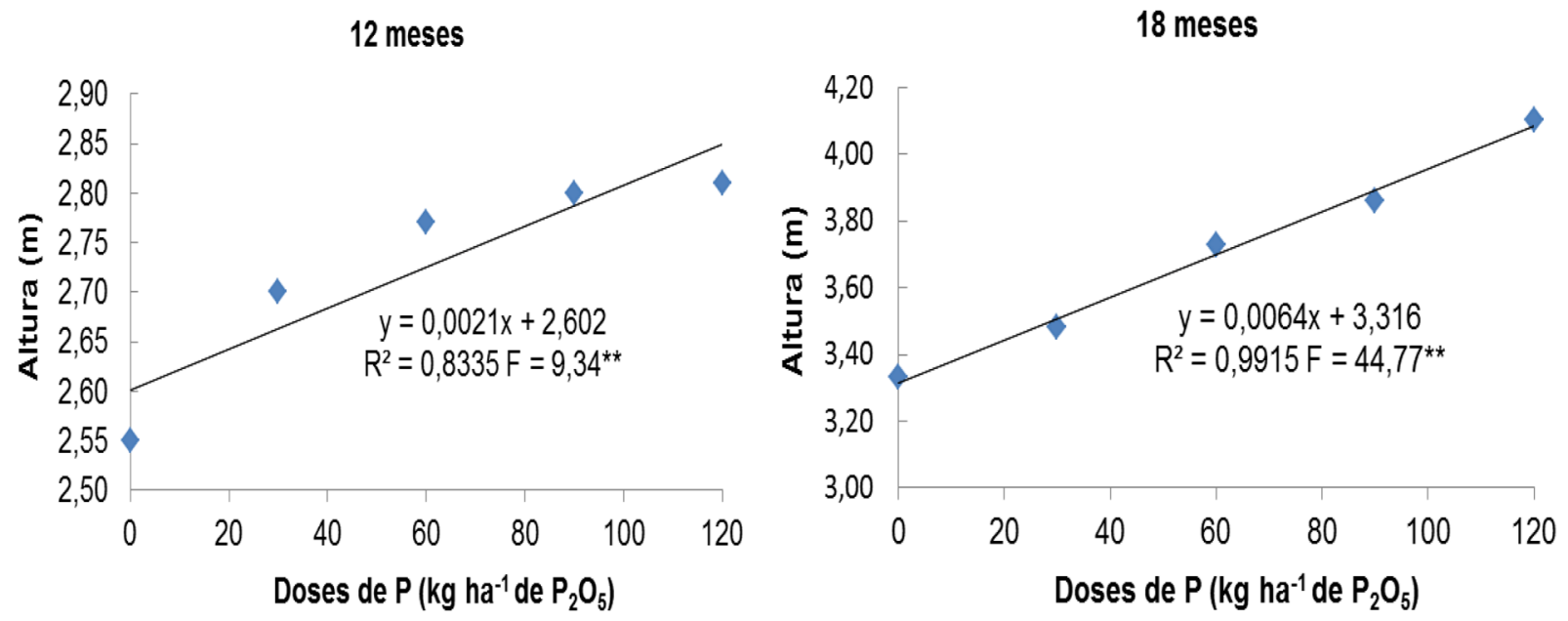

24 meses

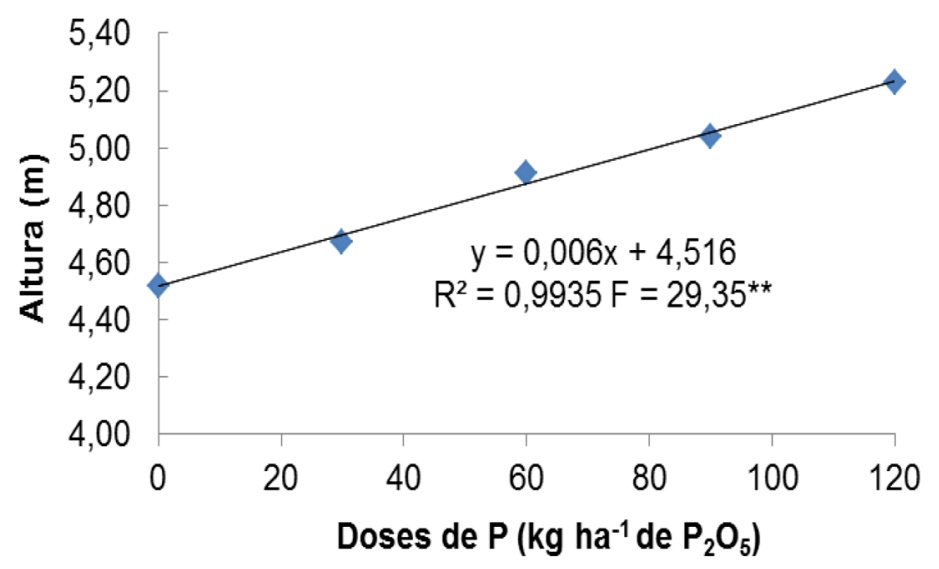

Figura 2. Altura de plantas de Khaya senegalensis em função das doses de fósforo aos 12, 18 e 24 meses de idade, Monte Alto - SP, 2016.

Figure 2. Height of Khaya senegalensis plants fertilized by phosphorus dosages at 12,18 and 24 months of age, Monte Alto -SP, 2016. 
12 meses

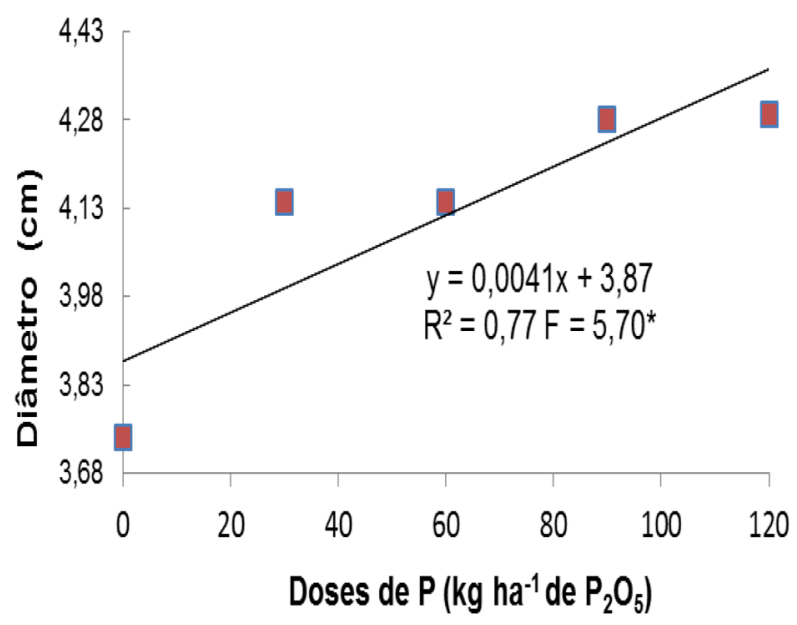

18 meses

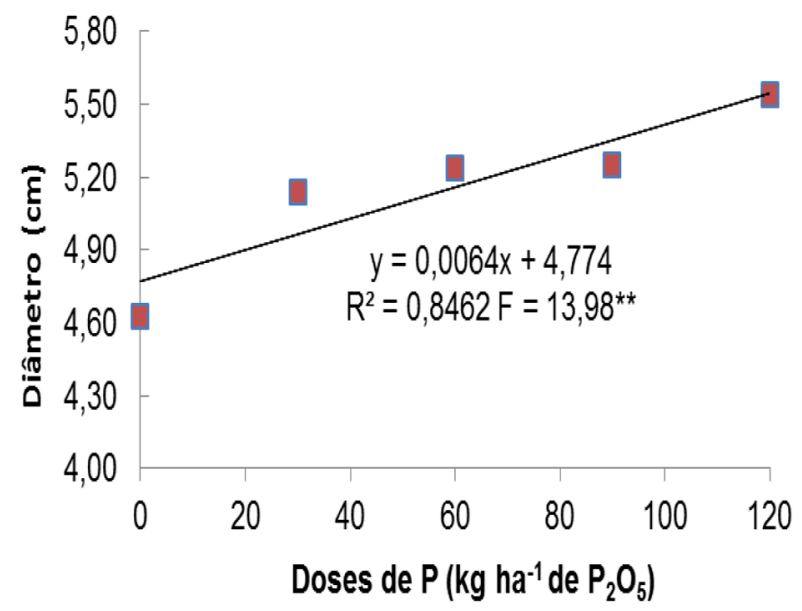

24 meses

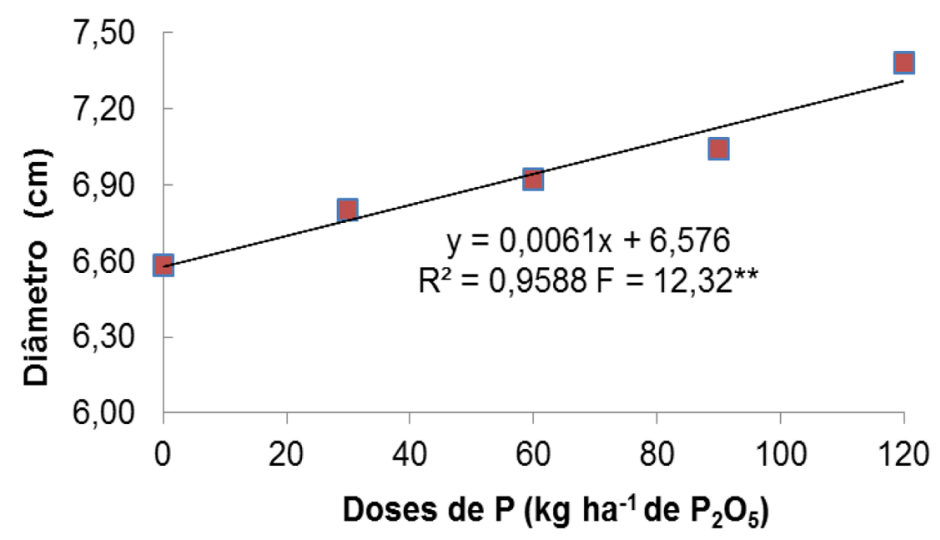

Figura 3. Diâmetro do caule a 1,3 m do solo (DAP) de plantas de Khaya senegalensis em função das doses de fósforo aos 12, 18 e 24 meses de idade, Monte Alto - SP, 2016.

Figure 3. Stem diameter at $1.3 \mathrm{~m}(\mathrm{DBH})$ of Khaya senegalensis plants fertilized by phosphorus dosages at 12,18 and 24 months of age, Monte Alto - SP, 2016.

Assim como no presente trabalho, pesquisadores australianos, através de levantamentos em plantios comerciais de K. senegalensis, notaram que o crescimento das plantas foi comprometido a partir do primeiro ano quando não foi aplicado fósforo no plantio (BEVEGE et al., 2006).

Estudos em vasos com plantas de K. senegalensis também mostram a importância de fósforo para a espécie já nas primeiras fases de desenvolvimento, quando a omissão de fósforo também causou a redução de crescimento em altura, diâmetro e também matéria seca de mudas de K. senegalensis (NWOBOSHI, 1982; RANCE et al., 1983).

Assim como a omissão, a fertilização fosfatada também tem causado rápidas respostas no crescimento de plantas do gênero Khaya em vasos. A aplicação de $125 \mathrm{mg} \mathrm{dm}^{-3}$ de P promoveu máximo crescimento em altura $(73 \mathrm{~cm})$ e diâmetro do caule $(26,3 \mathrm{~mm})$, e a aplicação de $185 \mathrm{mg} \mathrm{dm}^{-3}$ de P promoveu máxima massa seca total das plantas de K. senegalensis cultivadas em vasos, aos 180 dias do plantio (OLIVEIRA et al., 2015). Corcioli et al. (2014) também verificaram que a aplicação de fósforo foi essencial para desenvolvimento das plantas de Khaya ivorensis aos 55 dias após o início dos tratamentos nutricionais, mostrando também a rápida resposta da fertilização fosfatada para esta outra espécie do gênero Khaya.

Esse efeito rápido do fósforo mostra a importância da aplicação da dose de fósforo adequada desde a implantação da cultura (GRANT et al., 2001). O fósforo desempenha papel importante na fotossíntese, respiração, divisão e crescimento celular e na transferência de energia como parte do trifosfato de adenosina (ATP) (DECHEN; NACHTIGALL, 2007) e promove o crescimento do sistema radicular (GONÇALVES; BENEDETTI, 2000), além de influenciar na contração radial e tangencial da madeira (MOYA et al., 2010). Portanto, sua falta limita o crescimento das plantas desde a fase de implantação. 
Um experimento de omissão sob condições de campo foi realizado na Austrália, e vem sendo conduzido por 12 anos. O tratamento completo constou de $214 \mathrm{~kg} \mathrm{ha}^{-1} \mathrm{de} \mathrm{N} ; 192,36 \mathrm{~kg} \mathrm{ha}^{-1}$ de $\mathrm{P}_{2} \mathrm{O}_{5^{\prime}} ; 150,57 \mathrm{~kg} \mathrm{ha}^{-1}$ de $\mathrm{K}_{2} \mathrm{O} ; 87 \mathrm{~kg} \mathrm{ha}^{-1}$ de S e $174 \mathrm{~kg} \mathrm{ha}^{-1}$ de Ca, mais micronutrientes. Foi verificado, aos dois anos de idade, que as plantas cultivadas na omissão de fósforo apresentaram 1,35 m a menos do que as árvores do tratamento completo. Aos seis anos, essa diferença aumentou para 2,30 m. A partir do sexto ano, foi avaliado somente o DAP (diâmetro a 1,30 m do solo) das plantas. Aos seis anos a diferença entre a omissão e o tratamento completo foi de $3,80 \mathrm{~cm}$ de DAP e aos doze anos a diferença aumentou para $4,80 \mathrm{~cm}$. A omissão de fósforo só não limitou mais o crescimento do que a omissão conjunta de todos os nutrientes (BEVEGE et al, 2006). De acordo com esses autores, o fósforo é o nutriente limita mais e mais rapidamente o crescimento de K. senegalensis, sendo que a planta não se recupera dos efeitos negativos da sua omissão mesmo após 12 anos de cultivo.

Com relação às concentrações de macronutrientes nas folhas de K. senegalensis aos 12 meses após o plantio, o aumento das doses de fósforo elevou a concentração de potássio e reduziu a de enxofre (Figura 4).
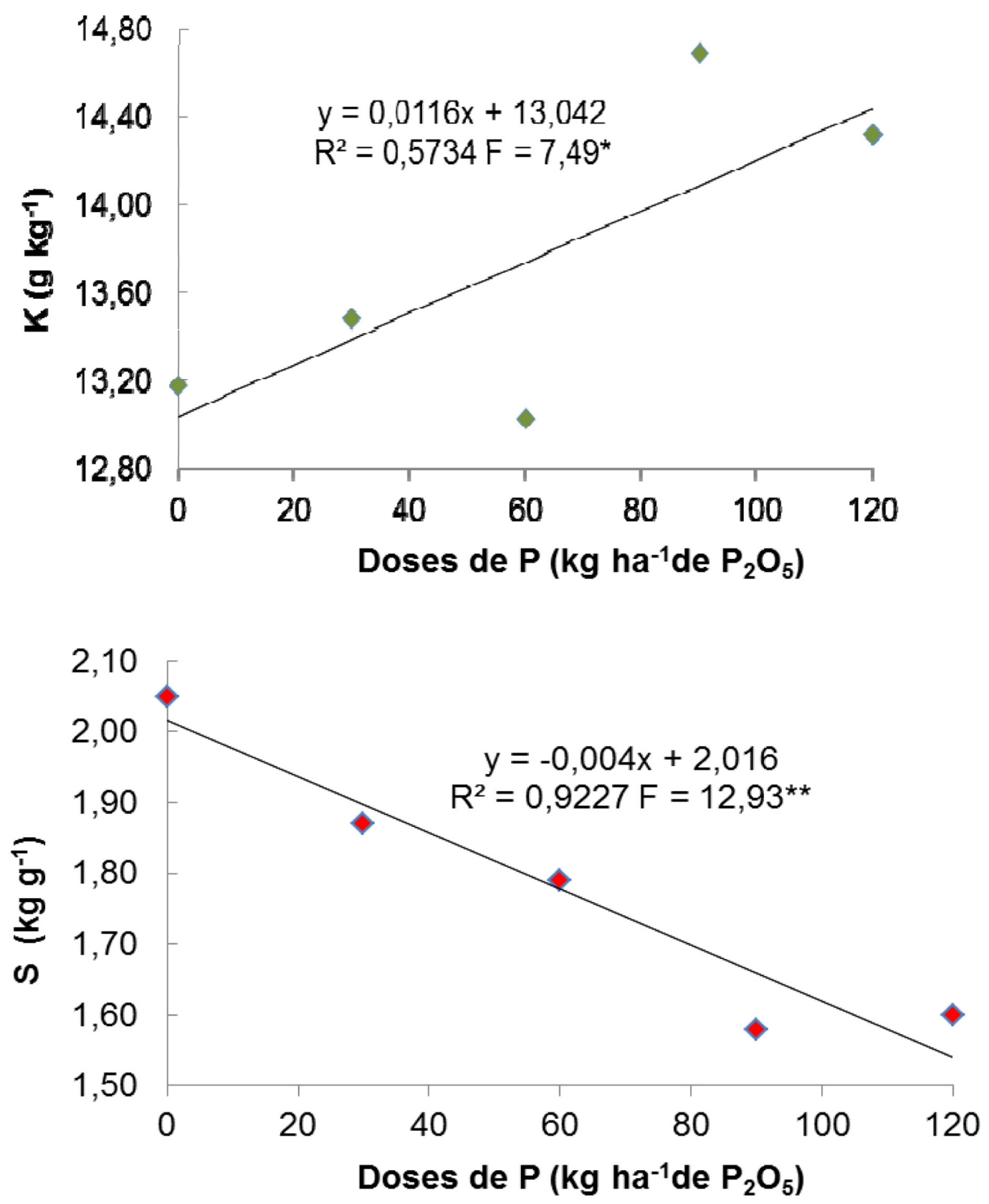

Figura 4. Concentração de potássio e enxofre nas folhas de plantas de Khaya senegalensis em função das doses de fósforo aos 12 de idade, Monte Alto - SP, 2016.

Figure 4. Concentration of potassium and sulfur in leaves of Khaya senegalensis plants fertilized by phosphorus dosages at age 12, Monte Alto - SP, 2016. 
As plantas que receberam maiores quantidades de fósforo tiveram maior crescimento em altura e diâmetro, o que pode ter causado um efeito de diluição na concentração de enxofre nas folhas, fato relatado na literatura (JARRELL; BEVERLY, 1981). Nwoboshi (1982) verificou que a omissão de fósforo refletiu em redução significativa na concentração do mesmo nas folhas além de um efeito secundário de decréscimo da concentração de cálcio e magnésio nas folhas. Esses resultados não se repetiram no presente trabalho. Alves (2013), aplicando solução nutritiva completa, com macro e micronutrientes, sob a forma de maxsol ${ }^{\circledR}$ não verificou diferenças nas concentrações de macro e micronutrientes na matéria seca total das plantas de K. senegalensis em tratamentos com e sem adição de solução.

De modo geral, as concentrações foliares dos macronutrientes foram adequadas para as plantas de K. senegalensis aos 12 meses de idade, de acordo com a primeira aproximação de concentrações adequadas de macronutrientes nas folhas de povoamentos comerciais da espécie na Austrália (BEVEGE et al., 2006).

Não houve efeito das doses de fósforo na condutância estomática, fotossíntese e eficiência instantânea no uso da água das plantas de K. senegalensis aos 12 meses de idade, porém houve efeito linear positivo na transpiração.

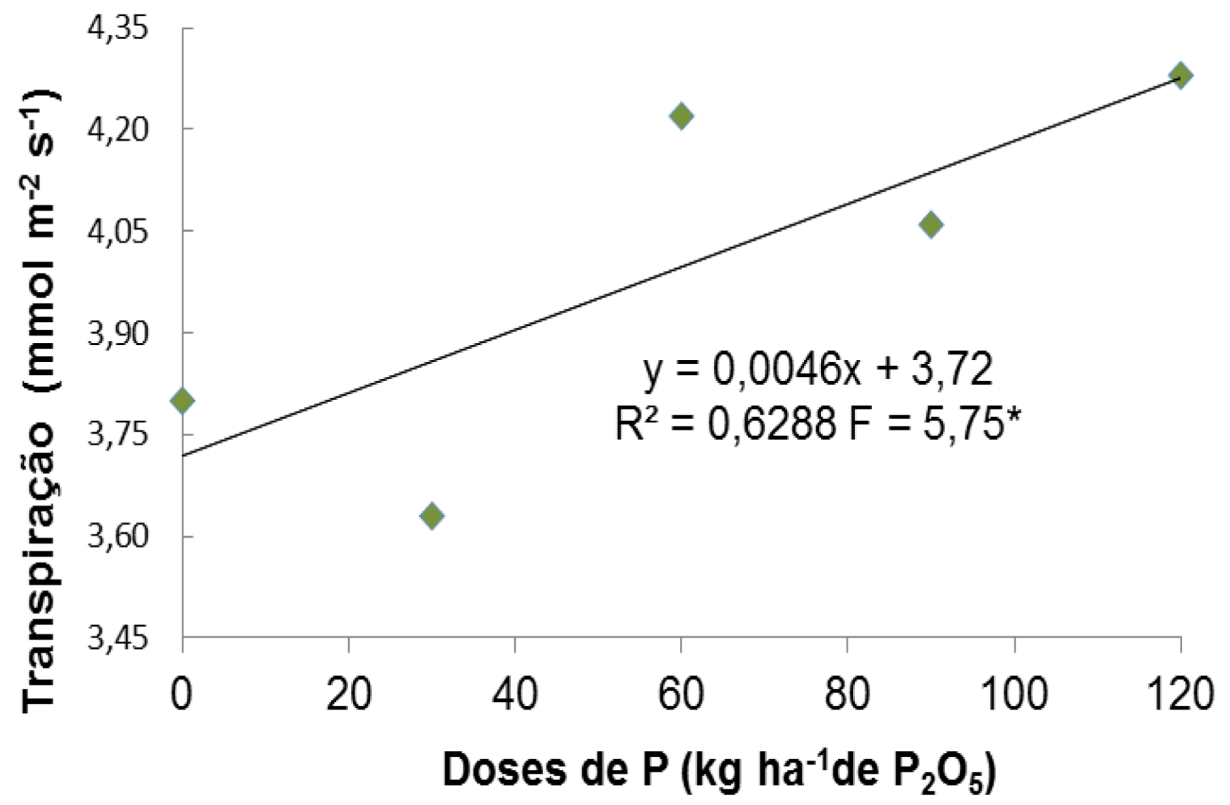

Figura 5. Transpiração de plantas de Khaya senegalensis em função das doses de fósforo aos 12 meses de idade, Monte Alto - SP, 2016.

Figure 5. Transpiration of Khaya senegalensis plants fertilized by phosphorus dosages at 12 months of age, Monte Alto - SP, Monte Alto - SP, 2016.

O aumento da transpiração não apresentou correlação com o aumento da concentração de potássio nas folhas $\left(0,29^{\text {ns; }} ; \mathrm{P}>0,05\right)$, indicando que não foi o aumento da concentração de potássio nas folhas que causou o aumento na transpiração.

O fato da coleta dos dados fisiológicos ter sido realizada no dia 25 de janeiro de 2015, em pleno verão, época em que o solo não apresentava limitação de água, favoreceu a manutenção da fotossíntese, condutância estomática e transpiração, mesmo nos tratamentos que receberam menores quantidades de fósforo, pois apesar de K. senegalensis ser uma espécie moderadamente tolerante o déficit hídrico (CALIXTO JÚNIOR et al., 2016), acentuada redução da disponibilidade de água no solo diminui o seu crescimento, sua transpiração, sua condutância estomática e sua taxa fotossintética e aumenta sua eficiência do uso da água (PEREZ et al., 2016).

De outro modo, em condições de menor disponibilidade de água, associada à baixa disponibilidade de fósforo no solo, pode ocorrer decréscimo da ciclagem de fósforo entre o citoplasma e o estroma das plantas (HENDRICKSON et al., 2004; SANTOS et al., 2006) e consequentemente, diminuição no consumo e produção de ATP e NADPH, menor carboxilação/regeneração de RuBP (SHUBHRA et al., 2004), decréscimo na expressão de genes relacionados à fotossíntese (LAWLOR; 
CORNIC, 2002), fechamento estomático (FLÜGGE et al., 2003) e menor condutância do mesofilo (LAWLOR; CORNIC, 2002). Portanto, em condições de restrição hídrica e baixa concentração de fósforo no solo, ocorre menor absorção do nutriente, menor atividade fotossintética e consequente redução do crescimento da planta.

\section{CONCLUSÕES}

A fertilização fosfatada no plantio de mogno-africano (Khaya senegalensis) em Argissolo com teor de fósforo muito baixo, favoreceu o crescimento das plantas no período entre um e dois anos de idade, promovendo aumento linear da altura e diâmetro à altura do peito com o aumento das doses até $120 \mathrm{~kg} \mathrm{ha}^{-1}$ de $\mathrm{P}_{2} \mathrm{O}_{5}$.

\section{REFERÊNCIAS BIBLIOGRÁFICAS}

ABPMA - ASSOCIAÇÃO BRASILEIRA DE PRODUTORES DE MOGNO AFRICANO. Khaya ivorensis. 2016. Disponível em: < http://abpma.org.br>. Acesso em: 13 jul. 2016.

ALVES, M. S. Produção e qualidade de mudas de mogno africano cultivadas com solução nutritiva. 2013. 63 p. Dissertação (Mestrado em Produção Vegetal) - Universidade Federal de Roraima, Boa Vista, 2013.

BATAGLIA, O. C.; FURLANI, A. M. C.; TEIXEIRA, J. P. F.; FRULAM, P. R.; GALLO, J. R. Métodos de análise química de plantas. Campinas: IAC, 1983. (Boletim Técnico, 78).

BLANCHAR, R. W.; REHM, G.; CALDWELL, A. C. Sulfur in plant material by digestion with nitric and perchloric acid. Proceedings of the Soil Science Society of America, Madison, v.29, p.71-72, 1963.

BRAGA, J. M.; DEFELIPO, B. V. Determinação espectrofotométrica de P em extratos de solo e material vegetal. Revista Ceres, Lavras, v. 21, p. 73-85, 1974.

BEVEGE, D. I.; NIKLES, D. G.; DICKINSON, G; SKELTON, D. J. Selecting soils and managing nutrition for Khay a senegalensis. Where to from here with $\mathrm{R} \& \mathrm{D}$ to underpin plantations of high-value timber species in the 'seasonally-dry' tropics of northern Australia? In: THE WORKSHOP IN TOWNSVILLE. 2006., Townsville. Proceedings... Kairi: Private Forestry North Queensland Association, 2006. 1 CD-ROM.

CAMARGO, O. A.; MONIZ, A. C.; JORGE, J. A.; VALADARES, J. M. A. S. Métodos de análise química, mineralógica e física de solos do Instituto Agronômico de Campinas. Campinas: IAC, 2009. 77 p. (Boletim técnico, 106).

CEPAGRI. CENTRO DE PESQUISAS METEOROLÓGICAS E CLIMÁTICAS APLICADAS A AGRICULTURA. Clima dos municípios paulistas. 2015. Disponível em: < http://www.cpa.unicamp.br/outras-informacoes/ clima muni 353.html >. Acesso em: 13 jul. 2016.

CLIMATE DATA - Climate: Tiakane. 2016. Disponível em: < http://en.climate-data.org/location/999743/>. Acesso em: 13 jul. 2016.

CORCIOLI, G.; BORGES J. D.; JESUS, R. P. Sintomas de deficiência nutricional de macronutrientes em mudas de Khaya ivorensis cultivadas em solução nutritiva. Pesquisa Florestal Brasileira, Colombo, v. 34, n. 78, p. 159-164, 2014.

COUTERON, P.; KOKOU, K. Woody vegetation spatial patterns in a semi-arid savanna of Burkina Faso, West Africa. Plant Ecology, Dordrecht, v. 132, n. 2, p. 211-227, 1997.

DECHEN, A. R.; NACHTIGALL, G. R. Elementos requeridos à nutrição de plantas. In: NOVAIS, R. F. et al. Fertilidade do solo. Viçosa: SBCS, 2007. p. 91-132. 
Costa et al. - Fertilização fosfatada na implantação de Khaya senegalensis A.Juss.

FLÜGGE, U. I.; HAUSLER, R. E.; LUDEWIG, F.; FISCHER, K. Functional genomics of phosphate antiport systems of plastids. Physiologia Plantarum, New Jersey, v. 118, n. 4, p. 475-482, 2003.

EMBRAPA - EMPRESA BRASILEIRA DE PESQUISA AGROPECUÁRIA. Sistema brasileiro de classificação de solos. Rio de Janeiro: Embrapa. 2006. 306 p.

GONÇALVES, J. L. M.; BENEDETTI, V. Produção de mudas de espécies nativas: substrato, nutrição, sombreamento e fertilização. In: GONÇALVES, J. L. M.; BENEDETTI, V. Nutrição e fertilização florestal. Piracicaba: IPEF, 2000. p. 309-350.

GRANT, C. A.; FLATEN, D. N.; TOMASIEWICZ, D. J.; SHEPPARD, S. C. A importância do fósforo no crescimento inicial da planta. Piracicaba: POTAFOS, 2001, 5 p. (Informações Agronômicas, 95).

HENDRICKSON, L.; CHOW, W. S.; FURBANK, R. T. Low temperature effects on grapevine photosynthesis: the role of inorganic phosphate. Functional Plant Biology, Clayton, v. 31, n. 8, p. 789-801, 2004.

ITTO - INTERNACIONAL TROPICAL TIMBER ORGANIZATION. Tropical Timber Market Report, v. 20, n. 14 , p. 1-23, 2016.

JARRELL, W. M.; BEVERLY, R. B. The dilution effect in plant nutrition studies. Advances in Agronomy, Amsterdan, v. 34, n 1, p. 197-224, 1981.

JOKER, D.; GAMÉNÉ, S. Khaya senegalensis (Desr.) A. Juss. Humlebaek: seed leaflet,, 2012. Disponível em: < http://curis.ku.dk/portallife/files/20648230/khayasenegalensis_int.pdf >. Acesso em: 20 jun. 2016.

KÖEPPEN, W. Climatologia: com um estúdio de los climas de la tierra. Mexico: Fondo de Cultura Econômica, 1948. $478 \mathrm{p}$.

LAMPRECHT H. Silvicultura nos trópicos: ecossistemas florestais e respectivas espécies arbóreas possibilidades e métodos de aproveitamento sustentado. Rossdorf: Deutsche Gesellschaft für Technische Zusammenarbeit, 1990. 343 p.

LAWLOR, D. W.; CORNIC, G. Photosynthetic carbon and associated metabolism in relation to water deficits in higher plants. Plant, Cell and Environment, Londres, v. 25, n. 2, p. 275-294, 2002.

LIMA, V. G. Estudio técnico económico para estabelecer una plantación de caoba africana (Khaya senegalensis) en el valle del Yeguare, Honduras. 2002. 42 p. Monografia (Graduação em Agronomia) Zamorano Carrera de Desarrollo sócio econômico y ambiente, San Antonio do Oriente, 2002.

CALIXTO JUNIOR, J. E. D.; RIOS, J. M.; MATOS, F. S.; SILVEIRA, P. S.; BARRETO. V. C. M.; FREITAS, I. A. S.; ARAUJO, M. S. Growth of Khaya senegalensis plant under water deficit. African Journal of Agricultural Research, Nairobi, v. 11, n. 18, p. 1623-1628, 2016.

MOYA, R. et al. Efeito das propriedades físicas e químicas do solo em algumas propriedades da madeira de teca (Tectona grandis). Revista Árvore, Viçosa, v. 34, n. 6, p. 1109-1118, 2010.

NIKLES D. G. Developing African mahogany (Khaya senegalensis) germplasm and its management for a sustainable forest plantation industry in northern Australia: progress and needs. Australian Forestry, Yarralumla, v. 71, n. 1, p. 33-47, 2008.

NWOBOSHI, L. C. Indices of macronutrient deficiencies in Khaya senegalensis. Communications in Soil Science and Plant Analysis, Philadelphia, v. 13, n. 8, p. 666-682, 1982. 
OLIVEIRA, C. S. Efeito do fósforo no desenvolvimento inicial de plantas de mogno-africano. 2015.18 p. Dissertação (Mestrado em Produção Vegetal) - Universidade Estadual de Goiás, Ipameri, 2015.

OLIVEIRA, J. B. Classificação de solos usada em levantamentos pedológicos no Brasil. Brasilia: EMBRAPA, 1999.

ORWA C.; JAMNADASS, R. H.; KINDT, R.; MUTUA, A.; SIMONS, A. Agroforestree Database: a tree reference and selection guide version 4.0. 2009. Disponível em: < http://www.worldagroforestry.org/treedb2/AFTPDFS/ Khaya senegalensis.pdf >. Acesso em 13 jul. 2016.

PEREZ, B. A. P.; VALERI, S. V; CRUZ, M. C. P.; VASCONCELOS, R. T. Potassium doses for African mahogany plants growth under two hydric conditions. African Journal of Agricultural Research, Nairobi, v. 11, n. 22, p. 1973-1979, 2016.

PINHEIRO A. L.; COUTO, L.; PINHEIRO, D. T.; BRUNETTA, J. M. F. Ecologia, silvicultura e tecnologia de utilização dos mognos-africanos (Khaya spp.). Viçosa: Sociedade de Agrossilvicultura, 2011. 102 p.

RAIJ, B.; ANDRADE, J. C.; CANTARELLA, H.; QUAGGIO, J. A. Análise química para avaliação da fertilidade de solos tropicais. Campinas: IAC, 2001. 285 p.

RANCE, S. J.; CAMERON, D. M.; WILLIAMS, E. R. Nutritional requirements and interactions of Khaya senegalensis on tropical red and yellow earths. Communications in Soil Science and Plant Analysis, Philadelphia, v. 14, n. 2, p. 167-183, 1983.

SANTOS, M. G.; RIBEIRO, R. V.; OLIVEIRA, R. F.; MACHADO, E. C.; PIMENTAL, C. The role of inorganic phosphate on photosynthesis recovery of common bean after a mild water deficit. Plant Science, Florida, v. 170 , n. 3, p. 659-664, 2006.

SHUBHRA J.; DAYAL, J.; GOSWAMI, C. L.; MUNJAL, R. Influence of phosphorus application on water relations, biochemical parameters and gum content in cluster bean under water deficit. Biologia Plantarum, Prague v. 48, n. 3, p. 445-448, 2004.

Recebido em 12/12/2017

Aceito para publicação em 28/06/2017

Sci. For., Piracicaba, v. 45, n. 116, p. 641-651, dez. 2017 DOI: dx.doi.org/10.18671/scifor.v45n116.05 
